\title{
Structure and variability of bat social calls: implications for specificity and individual recognition
}

\author{
Guido Pfalzer and Jürgen Kusch* \\ Department of Ecology, Faculty of Biology, University of Kaiserslautern, Erwin-Schroedinger-Strasse 13/14, 67663 Kaiserslautern, Germany \\ (Accepted 30 January 2003)
}

\begin{abstract}
Communication sounds or 'social calls' of 16 European bat species (Chiroptera, Vespertilionidae) were recorded at a range of roost and foraging sites. A comparative analysis of more than 5400 individual calls for general structures and for inter- as well as intraspecific variability resulted in 50 types of calls, which differed by their specific structure and by the calling species. These types could be grouped into four different general types of calls, according to the kind and complexity of their structure, independent of the calling species. Distinct types of calls seem to have similar functions in different bat species. One general type may be used predominantly in female-infant interactions as an isolation or direction call, which serves as mutual recognition. This type of social call was also used in 'tandem flights' of pairs of bats, which might increase individual knowledge of roost sites and foraging success. A second type was used in mate attraction, and a further one in an aggressive context. The fourth one was used by hindered or distressed bats. The group of 'aggressive' calls is least variable, but the complex mating calls and isolation calls are very diverse. Species-specific sound structures were identified, which allowed a computational species distinction. The measured inter-individual variability of social calls should be significant for their functions in individual recognition. So, beyond common features concerning the frequency structure of bat social calls, interspecific differences, as well as the intraspecific variability of details of sonagraphic parameters, should elucidate the specific functions of the calls.
\end{abstract}

Key words: bats, Chiroptera, communication, individual recognition, social calls

\section{INTRODUCTION}

Vocal signals for echolocation in bat species are well documented and their functions have been analysed, but the characteristics of calls and their use in communication processes are less well known. Intraspecific communication in bats includes olfactory, tactile and acoustic signals (Fenton, 1985). Long-distance transfer of information between individuals probably occurs solely by social calls, and short-distance communication (e.g. in maternity roosts) frequently occurs by acoustic signals. To increase the range of social calls, their frequency is often relatively low, compared to echolocation calls.

In principle, echolocation calls of bats (Fig. 1) can also have information for conspecifics, such as the presence and location of other individuals (Barclay, Fenton \& Thomas, 1979; Fenton \& Bell, 1981; Barclay, 1982; Avery, Racey \& Fenton, 1984; Leonard \& Fenton, 1984; Fenton, 1985, 1986; Balcombe \& Fenton, 1988; Masters \& Jacobs, 1989; Wilkinson, 1992a, 1995; Masters, Raver \& Kazial, 1995; Obrist, 1995). Echolocation calls evolved

*All correspondence to: J. Kusch.

E-mail: kusch@rhrk.uni-kl.de alongside species-specific environmental adaptations, e.g. different foraging sites that selected for corresponding echolocation transmitting and sensing features. Many bat species use different echolocation calls, adapted to their habitat structure or foraging situation (Miller \& Degn, 1981; Fenton, 1987; Rydell, 1990; Kalko, Schnitzler \& Schnitzler, 1993; Jones, 1995). Calls of constant and relatively low frequencies, e.g. at $20 \mathrm{kHz}$ in Nyctalus noctula, are used above open areas of foraging habitats, whereas calls of variable frequencies, e.g. from 60 to $30 \mathrm{kHz}$ in $N$. noctula, are used in structured habitats with trees or other interspersed elements. Frequency, frequency variability, and repeat number of calls per time also depend on the foraging situation of bats, and therefore often cause large intraspecific diversity of echolocation calls (Griffin, Webster \& Michael, 1960; Kalko, Schnitzler \& Schnitzler, 1989).

'Social' calls are vocalizations produced in addition to echolocation calls, and carry information to conspecifics. Since echolocation calls also may give information to conspecifics, a total separation of both types of calls is not possible (Fenton, 1985). Yet, social calls differ from echolocation calls by their solely communicational function. Therefore a behavioural differentiation of both 


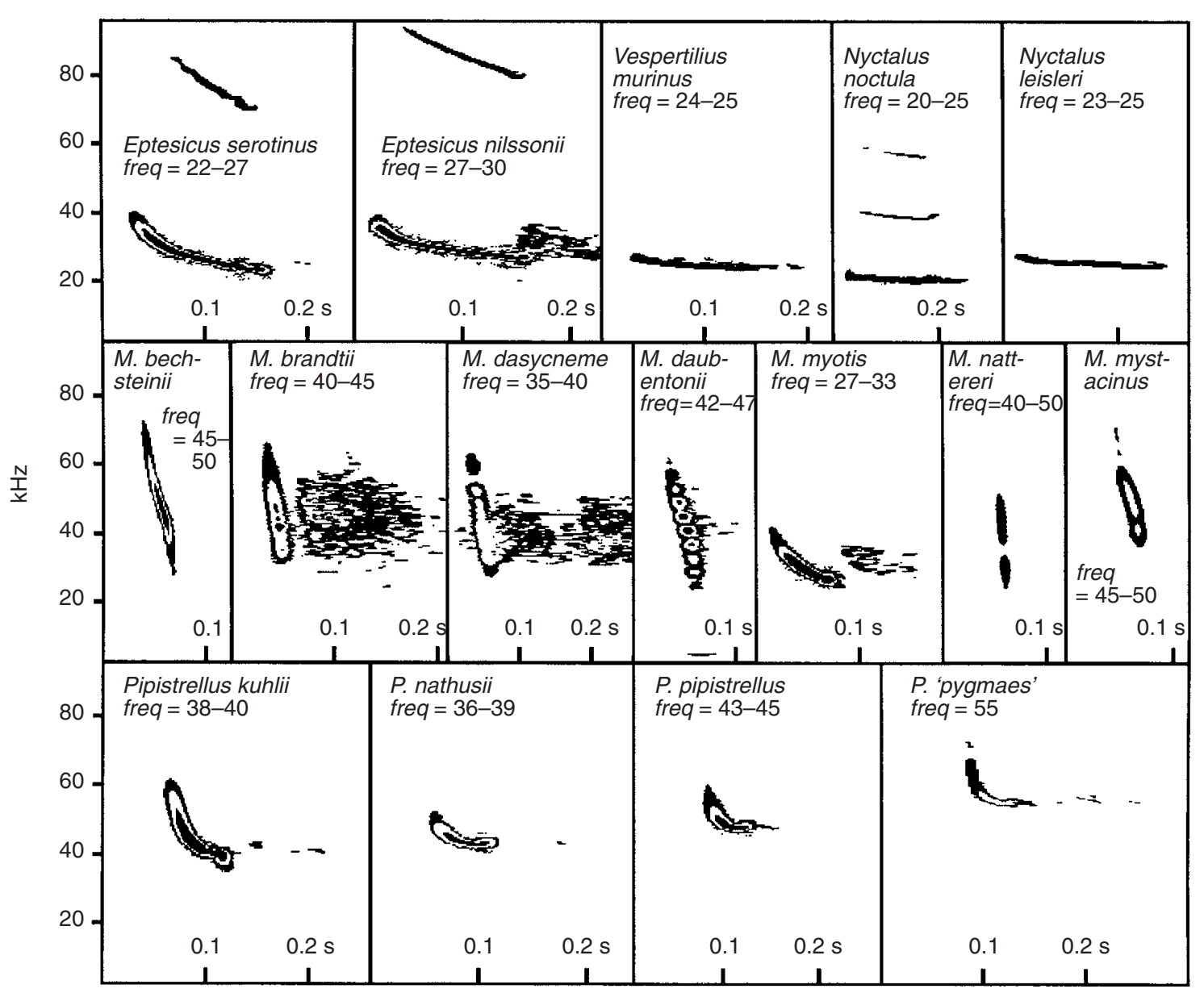

Fig. 1. Sonagrams of echolocation calls of 16 European bat species. Calls were chosen of those bat species whose social calls were investigated in the present study. Figures show typical echolocation calls of the species, but note that large variability occurs in some species. freq, frequencies with most energy.

groups of calls is possible. Whereas echolocation calls are typically produced continuously throughout the flight of a bat, social calls are vocalized occasionally during flight in various situations, and also from resting animals, especially at roost sites. A structural differentiation of social calls from echolocation calls in general may not be possible, because of the wide variability of both functional groups of calls. Social calls are shaped by selective factors that may differ from those that influence echolocation calls. They should be both species-specific and more diverse than echolocation calls, depending on the number and kinds of information to be transmitted, and the different situations where they are used (Fenton, 1994). In general, acoustic social signals in bats are grouped into aggressive or warning calls, mating and song flight calls, distress calls, or isolation and direction calls.

Several descriptions of single or a few social call types of distinct bat species exist and try to make correlations to specific activities of the animals. 'Distress calls' are transmitted from bats in perilous situations and attract conspecifics. Possibly the resulting aggregation of individuals serves as a defence against predators (Fenton et al., 1976; Russ, Racey \& Jones, 1998). The 'advertisement song' of $N$. leisleri is produced from stationary as well as from flying individuals and may attract partners (Zingg, 1988; Helversen \& Helversen, 1994). Structural differences occur in individual social calls, and bats may thereby mutually recognize one another (e.g. Gelfand \& McCracken, 1986; Balcombe, 1990; Jones Hughes \& Rayner, 1991; Boughman, 1997).

Short-distance recognition was assumed to be achieved predominantly by olfactory signals (Kolb, 1977) and was observed in female-infant recognition of Rousettus aegyptiacus, Tadarida condylura and T. brasiliensis mexicana (Kulzer, 1958, 1962; Gustin \& McCracken, 1987). Infants of the latter species were not able to recognize their mothers solely by olfactory signals (Gustin \& McCracken, 1987). Additional acoustic signals are responsible for recognition of individuals. Indeed corresponding 'isolation calls' were identified and individual specific structures of the calls were detected (Kolb, 1981; Fenton, 1985). Females of bat colonies must find and recognize their pups among many individuals after foraging. Approximately 20 million individuals of T. brasiliensis inhabited the largest known bat colony (Altringham, 1996). A solely olfactory recognition seems to be impossible among such abundant animals. A presupposition for acoustic recognition of 
individuals is the high variability of their calls. Individual specific frequency structures of isolation calls were recognized in the colonial bats Antrozous pallidus (Brown, 1976), Desmodus rotundus (Schmidt, Joermann \& Schmidt, 1981), Myotis myotis (Kolb, 1981), M. lucifugus (Thomson, Fenton \& Barclay, 1985), Phyllostomus discolor (Rother \& Schmidt, 1985), Plecotus auritus (De Fanis \& Jones, 1995), T. brasiliensis mexicana (Balcombe, 1990), Pipistrellus pipistrellus s. l. (Jones et al., 1991) and in Nycticeius humeralis (Scherrer \& Wilkinson, 1993).

In the present work we describe and analyse a spectrum of available social calls of 16 European bat species concerning their individual characteristics, as well as their inter- and intraspecific variability. We develop structurally similar groups and discuss their potential function as communication signals in different bat species. We measure the interspecific variability of social calls. The degree of inter-individual differences in details of sonagraphic parameters of calls and the potential significance for a function as individual recognition signals is evaluated.

\section{METHODS}

\section{Field recordings}

From May 1998 to October 2000, the social calls of 16 bat species belonging to 5 genera were recorded. Bats were studied in the forest region 'Pfälzerwald' $\left(49^{\circ} 18^{\prime}-49^{\circ} 28^{\prime} \mathrm{N}, 7^{\circ} 40^{\prime}-7^{\circ} 55^{\prime} \mathrm{E}\right)$ and in several urban regions in south-west Germany, and in Luxembourg. Distances between several roost sites of individual species were $<30 \mathrm{~km}$. Social calls of Pipistrellus kuhlii were recorded at the Mediterranean coast of the Spanish region of Catalonia. Different foraging sites as well as various types and locations of roosts were studied, including tree holes, attics or roof ridges of houses and churches, bat boxes and a cave. Bat species were identified morphologically and additionally by echolocation calls in some species. Bats in tree holes were located and identified by using a medical endoscope. Behavioural observations were made using a night vision scope.

Acoustic recordings were made using a portable ultrasound detector and processor (Laar bridge box, BVL von Laar, Bottrop, Germany). The CK40 microphone of the detector has flat frequency response for frequencies between 20 and $80 \mathrm{kHz}$; using an amplifier, a flat sensitivity of up to $170 \mathrm{kHz}$ was achieved. The processor sampled at a rate of $400 \mathrm{kHz}$ and time-expanded 10 fold a $5.12 \mathrm{~s}$ digitally recorded sequence. The resulting sequence, lasting $51.2 \mathrm{~s}$, was then replayed and recorded digitally on a Sony TCD-D8 DAT-recorder.

\section{Sound analysis}

The recordings were analysed with the software Voxscope Professional (Avisoft, Berlin). A sampling frequency of
22050 samples/s, with 16 bits/sample was used. A 512 pt. FFT with a Hamming window was used for analyses. Oscillograms, frequency spectra and sonagrams were evaluated. For each social call, the following parameters of the call (Fig. 2) were measured: total duration (dur); minimum frequency ( $f$ min); maximum frequency ( $f$ max); frequency of highest energy (freq); according to Russo $\&$ Jones (1999). The change of frequency per pulse with time ( $c f p$ ) was measured to indicate a modulation of the call frequency (FM-calls) or a constant frequency (CFcalls). Additionally, in social calls consisting of several components, the number of call elements (pulses) per time were measured as well as individual values of fmin, fmax and freq of the pulses. If $>1$ harmonic was present, values of the first (fundamental) harmonic were taken. The number of different pulses per call is given by difptype. If not mentioned otherwise, the term 'frequency' is used throughout the text to describe the parameter oscillation speed $(\mathrm{kHz})$ of the call, but not the number of calls per time (rate). Parameters were measured from sonagram computer files with the help of the automatic parameter measurement options of the Voxscope Professional software.

\section{Statistical analysis}

Discriminant function analysis of call variability was used to test for discrimination of social call types into interspecific and intraspecific groups and to find which call parameters contribute most to group separation. For the discrimination of 4 general types of social calls, independent of the species, all 7 measured parameters were used as variables. In all other tests for discrimination of call groups, variables were the measured call parameters dur, fmin, fmax and freq of calls and call elements. Naturally occurring groups to be distinguished were either call types, bat species, or calls of individuals or of different roosts of single species. Probability plots were analysed for a normal distribution of the data. The relative contribution of each of the variables $(j)$ is represented by its standardized discriminant function coefficient $\overline{b_{j}}$ :

$$
\overline{b_{j}}=\sum_{k=1}^{k}\left|b_{j k}\right| \cdot E A_{k},
$$

where $E A_{\mathrm{k}}$ is the proportionate eigenvalue of the canonical discriminant function $k$ and $\left|b_{j k}\right|$ is the absolute coefficient value.

For predictions of the group membership of calls, the classification function of the statistical software was used, using the split-sample procedure to check the precision of group discrimination. Thereby the data were split and half of the calls were used to produce the discriminant functions. These functions were then used to classify the remaining half of the calls. Analyses was done with the software Statistica (StatSoft). 

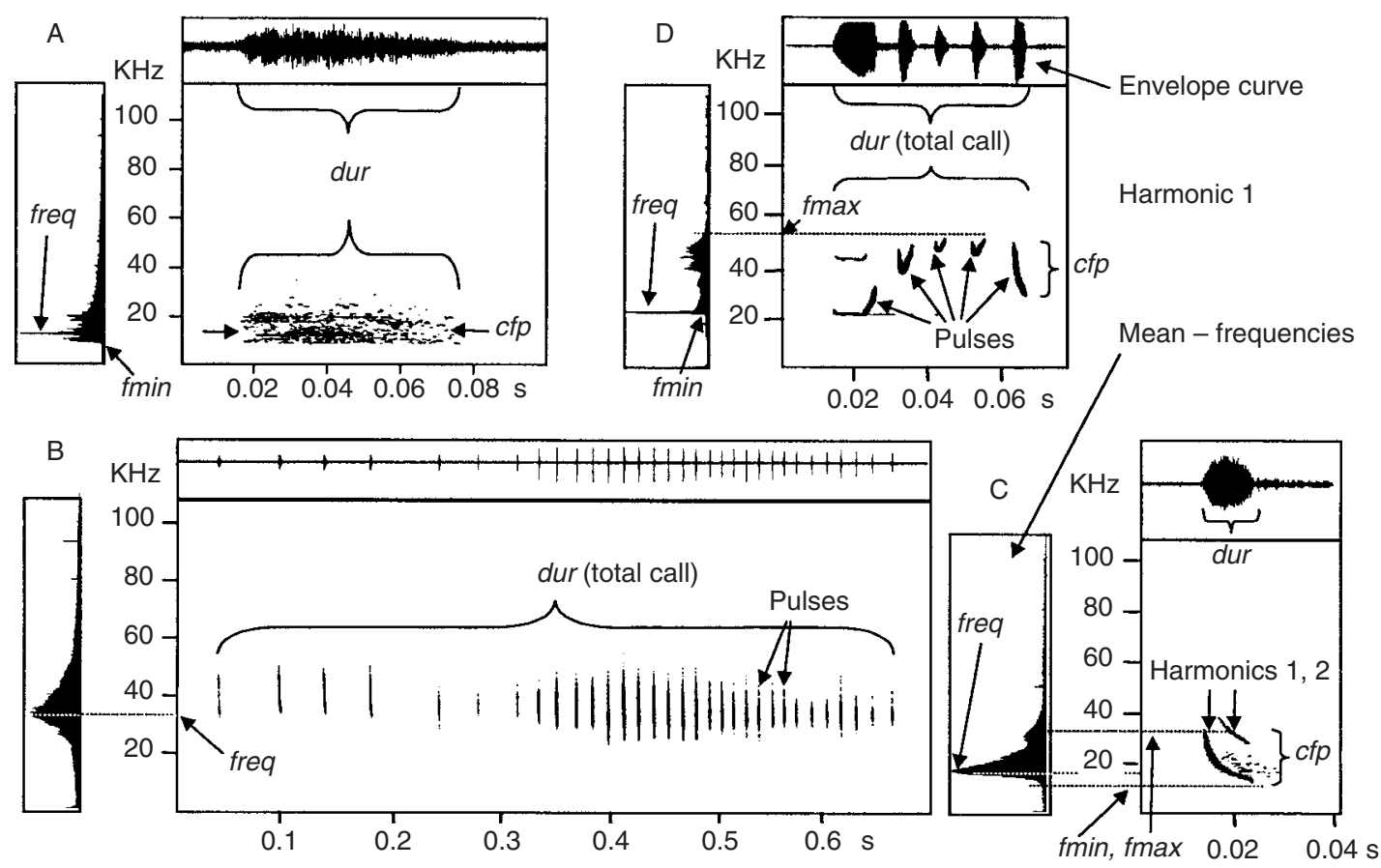

Fig. 2. Sonagrams of social calls of types A, B, C and D of Nyctalus noctula giving the change of frequency with time. Envelope curves, or 'waveforms' (upper part of sonagrams) give the change of amplitude with time. Mean frequencies (left part of sonagrams) give the amplitude of different frequencies as the average of the shown (or measured) time window. A, Call type which has a constant frequency range ('CF') during time (horizontal course); B, C, D, call types where frequencies are modulated with time (vertical change of course; 'FM'). Those parameters are given that were evaluated in the present work.

Table 1. Bat species, sites or events where social calls of bats were recorded, and number of sites or periods of recordings ( $n$ ). Letters represent the different types of social calls according to Table 2

\begin{tabular}{|c|c|c|c|c|c|c|}
\hline Species & $n$ & Mating roost & Maternity roost & During flight & Foraging habitat & Distress situation \\
\hline Eptesicus nilssonii & 1 & & & & & $\mathrm{C}$ \\
\hline E. serotinus & 13 & & A, B, C, D & & & \\
\hline Myotis bechsteinii & 6 & & $\mathrm{~A}, \mathrm{~B}, \mathrm{C} 1, \mathrm{C} 2$ & $\mathrm{C} 1$ & & \\
\hline M. brandtii & 2 & & $\mathrm{~A}, \mathrm{~B}, \mathrm{C}, \mathrm{D}$ & & & \\
\hline M. dasycneme & 1 & & & & & B \\
\hline M. daubentonii & 15 & & & $\mathrm{C} 2, \mathrm{D}$ & $\mathrm{C} 1, \mathrm{C} 2$ & B \\
\hline M. myotis & 9 & $\mathrm{~A}, \mathrm{~B}, \mathrm{D}$ & $\mathrm{A}, \mathrm{B}, \mathrm{C}$ & & & B \\
\hline M. mystacinus & 2 & & & & & $\mathrm{~B}$ \\
\hline M. nattereri & 3 & & $\mathrm{~A}, \mathrm{~B}, \mathrm{D}$ & & & \\
\hline Nyctalus leisleri & 10 & $\mathrm{C} 2$ & $\mathrm{~A}, \mathrm{~B} 2, \mathrm{C} 1$ & $\mathrm{~B} 1, \mathrm{C} 1, \mathrm{C} 2, \mathrm{D}$ & $\mathrm{B} 1, \mathrm{D}$ & B \\
\hline N. noctula & 46 & $\mathrm{~A}, \mathrm{~B}, \mathrm{C} 1-\mathrm{C} 3, \mathrm{D} 1, \mathrm{D} 2$ & & $\mathrm{C} 1, \mathrm{D} 1, \mathrm{D} 2$ & D1 & \\
\hline Pipistrellus kuhlii & 4 & $\mathrm{D}$ & & $\mathrm{C}, \mathrm{D}$ & C, D & \\
\hline P. nathusii & 4 & $\mathrm{D}$ & & C, D & $\mathrm{D}$ & \\
\hline P. pipistrellus & 100 & $\mathrm{D}$ & $\mathrm{B}, \mathrm{C}$ & $\mathrm{D}$ & $\mathrm{D}$ & A, B \\
\hline P. pygmaeus & 9 & $\mathrm{D}$ & & $\mathrm{C}$ & $\mathrm{D}$ & \\
\hline Vespertilio murinus & 3 & $\mathrm{D}$ & & $\mathrm{D}$ & & \\
\hline
\end{tabular}

\section{RESULTS}

\section{Similar types of social calls occur in different bat species}

Social calls were emitted from bats in various situations at different roosts and foraging sites (Table 1). To detect and evaluate general structures as well as the interand intraspecific variability of the calls, 5400 timeexpanded calls were analysed. Fifty different types of calls, depending on the species and the sonagraphic structures, were distinguished (Fig. 3, Table 2). Characteristics of the various social calls were measured from sonagrams. The frequency values and duration, as well as their statistical variability are summarized in Table 2 .

Independent of the species, the calls could be grouped into four general types according to their sonagraphic structure: squawk-like (type A); repeated 'trills' (type B); cheep-like of curve structured sonagrams (type C); song-like with complex structured sonagrams (type D). Type A calls are noisy signals of constant, broad-band 


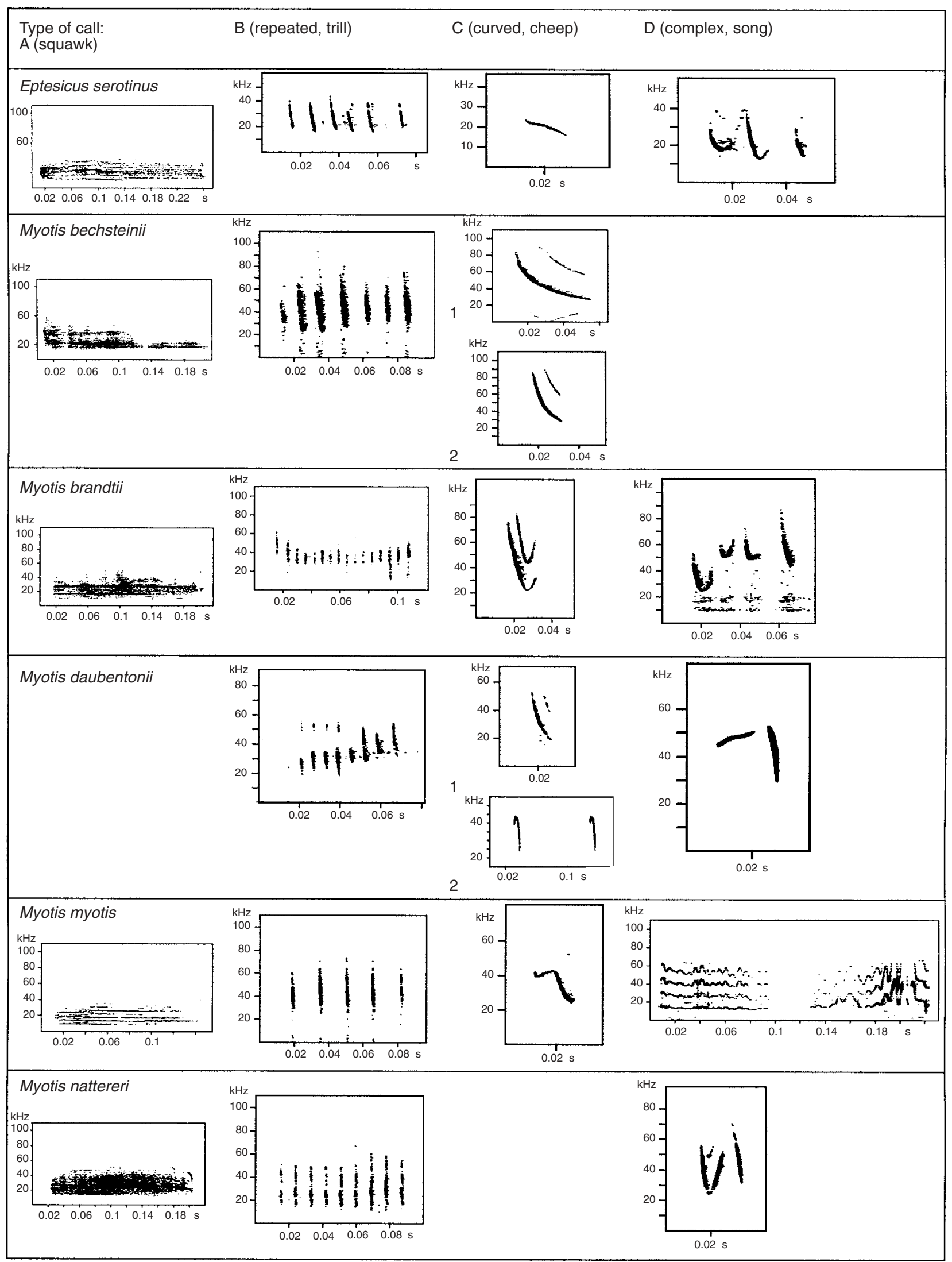

Fig. 3. For caption see page no. 26. 


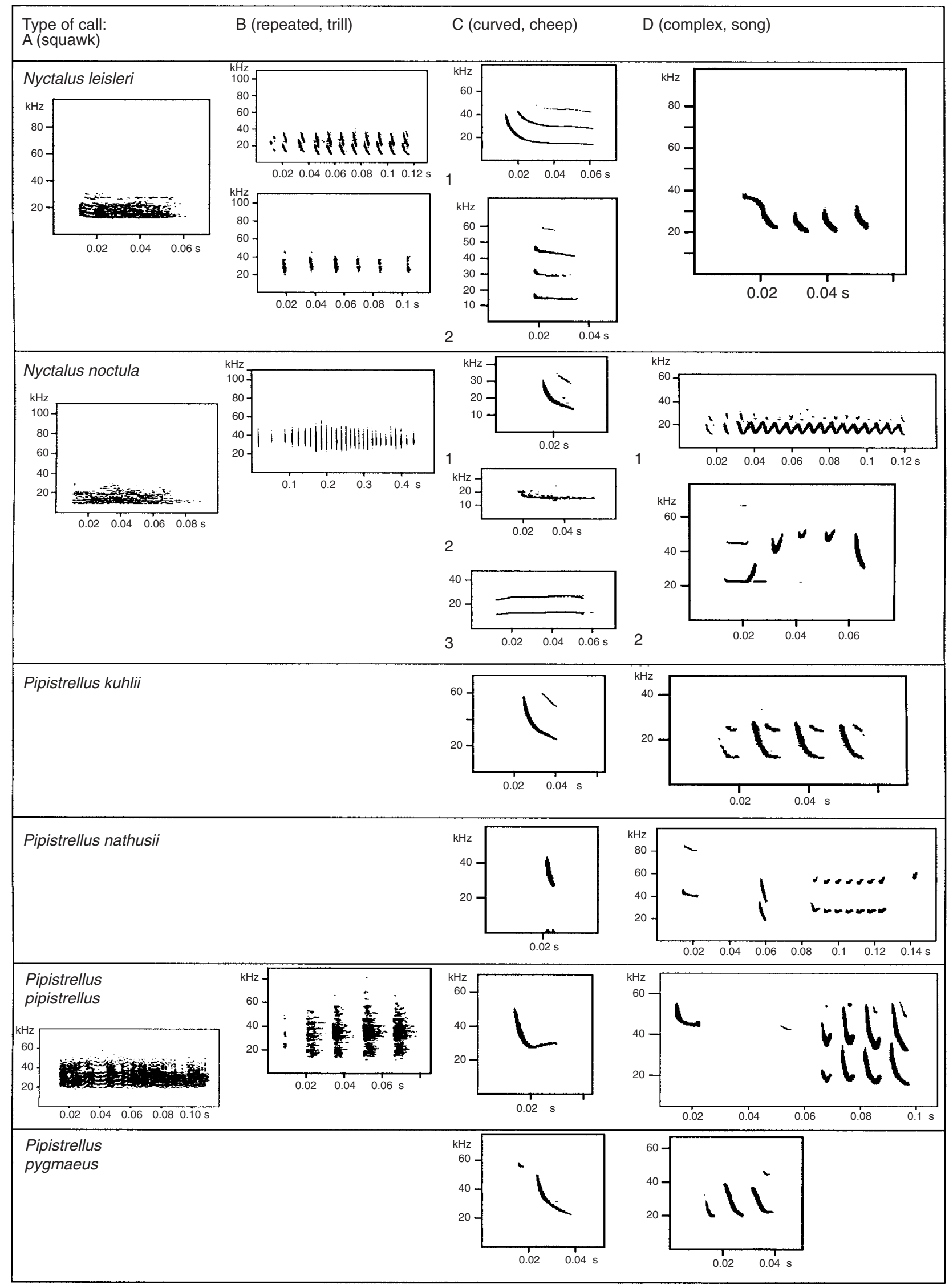

Fig. 3. Interspecific comparison of sonagrams of social calls of 12 European bat species, and four general types of calls distinguished. 
Table 2. Social call parameters from 16 European bat species. Data are given for call types with recorded numbers $\geqslant 3$ only. Median, 1 SEM, and number of calls evaluated (in parentheses) are given for dur, freq, fmax and fmin. Pulses, elements per call; cfp, change of frequency per pulse with time. Maximum $c f p$-values are given for calls with different pulses

\begin{tabular}{|c|c|c|c|c|c|c|c|}
\hline $\begin{array}{l}\text { Species, } \\
\text { type of call }\end{array}$ & $d u r(\mathrm{~ms})$ & freq $(\mathrm{kHz})$ & $f \max (\mathrm{kHz})$ & $f \min (\mathrm{kHz})$ & $\begin{array}{l}\text { pulses } \\
\text { (per } 0.01 \mathrm{~s})\end{array}$ & $c f p(\mathrm{kHz})$ & difptype \\
\hline E. serotinus, A & $198,74.0(18)$ & 21, $3.1(18)$ & & & 1 & 0 & 1 \\
\hline E. serotinus, B & $38,18.5(9)$ & $18,2.8(9)$ & $21,9.0(9)$ & $10,1.4(9)$ & 6 & 11 & 1 \\
\hline E. serotinus, C & $24,21.8(77)$ & $19,1.7(77)$ & $24,2.8(77)$ & $12,2.1(77)$ & 1 & 12 & 1 \\
\hline M. bechsteinii, A & $67.2,79.4(16)$ & $20.2,2.3(16)$ & & & 1 & 0 & 1 \\
\hline M. bechsteinii, B & $72.6,38.4(33)$ & $36.2,4.3(33)$ & $62.9,7.2(33)$ & $22.0,5.0(33)$ & 7 & 41 & 1 \\
\hline M. bechsteinii, $\mathrm{C} 1$ & $29.0,7.6(531)$ & $34.9,4.0(527)$ & $83.6,9.9(531)$ & $21.5,3.6(531)$ & 1 & 62 & 1 \\
\hline M. bechsteinii, C2 & $18.6,4.5(73)$ & $35.7,3.3(73)$ & $82.3,10.6(73)$ & $22.0,2.6(73)$ & 1 & 60 & 1 \\
\hline M. brandtii, A & $157.9,70.2(7)$ & $28.0,1.7(7)$ & & & 1 & 0 & 1 \\
\hline M. brandtii, B & $81.9,17.6(5)$ & $34.2,29.3(5)$ & $54.3,20.2(5)$ & $20.7,34.1(5)$ & 16 & 34 & 1 \\
\hline M. brandtii, $\mathrm{C}$ & $17.7,6.0(315)$ & $35.7,7.1(315)$ & $69.8,11.1(315)$ & $20.7,5.6(315)$ & 1 & 49 & 1 \\
\hline M. brandtii, D & $37.4,7.6(5)$ & $50.4,2.2(5)$ & $82.7,6.2(5)$ & $24.1,1.3(5)$ & 4 & 30 & 3 \\
\hline M. dasycneme, $\mathrm{B}$ & $65.0,51.7(3)$ & $31.4,2.4(3)$ & $57.3,1.3(3)$ & $18.9,1.7(3)$ & 8 & 38 & 1 \\
\hline M. daubentonii, $\mathrm{C} 1$ & $16.6,3.6(10)$ & $34.2,1.9(10)$ & $59.0,6.5(10)$ & $20.2,2.7(10)$ & 1 & 20 & 1 \\
\hline M. daubentonii, C2 & $9.9,2.0(69)$ & $42.2,4.8(69)$ & $47.4,5.4(69)$ & $26.7,2.6(69)$ & 2 & 21 & 1 \\
\hline M. daubentonii, D & $17.6,1.8(3)$ & $46.1,2.0(3)$ & $57.1,5.0(3)$ & $26.6,0.5(3)$ & 3 & 31 & 2 \\
\hline M. myotis, A & $136.1,89.2(17)$ & $15.5,1.5(17)$ & & & 1 & 0 & 1 \\
\hline M. myotis, B & $44.9,18.4(54)$ & $31.0,4.5(54)$ & $60.9,9.3(54)$ & $16.8,5.9(54)$ & 5 & 44 & 1 \\
\hline M. myotis, C & $29.0,7.9(237)$ & $25.0,7.8(237)$ & $53.4,9.1(237)$ & $19.8,3.7(237)$ & 1 & 34 & 1 \\
\hline M. myotis, D & $84.8,196.0(19)$ & 17.7, $7.8(19)$ & $33.6,14.5(19)$ & 11.6, $3.9(19)$ & 2 & 22 & 3 \\
\hline M. mystacinus, B & $40.9,6.9(11)$ & $36.2,1.5(11)$ & $55.6,2.8(11)$ & $27.1,1.4(11)$ & 9 & 29 & 1 \\
\hline M. nattereri, A & 173.0, 56.1(22) & $30.8,4.5(22)$ & & & 1 & 0 & 1 \\
\hline M. nattereri, B & $44.4,22.4(26)$ & $32.5,4.7(26)$ & $55.3,11.7(26)$ & $15.7,4.1(26)$ & 9 & 40 & 1 \\
\hline M. nattereri, D & $11.5,21.0(38)$ & $37.9,11.6(37)$ & $78.4,9.5(37)$ & $23.3,14.1(37)$ & 2 & 40 & 2 \\
\hline N. leisleri, A & $71.4,61.4(135)$ & $13.4,1.3(135)$ & & $8.6,0.9(135)$ & 1 & 0 & 1 \\
\hline N. leisleri, B1 & $121.1,70.9(12)$ & $18.7,3.7(12)$ & $26.1,2.8(12)$ & $9.0,0.3(12)$ & 9 & 17 & 1 \\
\hline N. leisleri, B2 & $111.5,37.2(18)$ & $31.2,3.5(18)$ & $46.9,3.4(18)$ & $18.3,3.2(18)$ & 6 & 29 & 1 \\
\hline N. leisleri, $\mathrm{C} 1$ & $45.0,10.7(37)$ & $15.1,1.3(37)$ & $31.9,9.6(37)$ & $13.4,1.4(37)$ & 1 & 19 & 1 \\
\hline N. leisleri, C2 & $15.4,4.7(324)$ & $13.8,0.7(324)$ & $17.7,1.2(324)$ & $12.1,0.7(324)$ & 1 & 6 & 1 \\
\hline N. leisleri, D & $38.0,7.7(36)$ & $22.4,1.2(36)$ & $38.1,3.2(36)$ & $20.2,0.9(36)$ & 2 & 18 & 2 \\
\hline N. noctula, A & $62.7,12.3(41)$ & $13.4,3.0(41)$ & & $8.2,0.4(41)$ & 1 & 0 & 1 \\
\hline N. noctula, B & $397.6,324.9(13)$ & $32.9,4.1(14)$ & & & 8 & 33 & 1 \\
\hline N. noctula, $\mathrm{C} 1$ & $15.1,4.1(111)$ & $15.5,1.2(111)$ & $32.3,8.3(111)$ & $10.8,1.1(111)$ & 2 & 22 & 1 \\
\hline N. noctula, $\mathrm{C} 2$ & $22.0,12.9(70)$ & $15.9,1.4(70)$ & & $13.6,1.6(70)$ & 1.5 & 6 & 1 \\
\hline N. noctula, C3 & $57.5,8.3(246)$ & $13.8,0.8(246)$ & $15.7,1.8(246)$ & $10.3,0.9(246)$ & 1 & 5 & 1 \\
\hline N. noctula, D1 & $81.6,24.3(117)$ & $17.7,1.9(113)$ & $24.1,3.8(117)$ & $10.3,1.3(117)$ & 4 & 14 & 2 \\
\hline N. noctula, D2 & $57.5,13.9(461)$ & $25.6,4.9(464)$ & $47.8,7.0(451)$ & $20.7,3.6(464)$ & 3 & 20 & 4 \\
\hline P. kuhlii, C & $17.6,2.9(4)$ & $28.0,0.7(4)$ & $59.0,7.8(4)$ & $20.2,5.4(4)$ & 1 & 29 & 1 \\
\hline P. kuhlii, D & $29.2,6.0(14)$ & $13.4,1.4(14)$ & $37.0,7.1(14)$ & $11.8,1.3(14)$ & 4 & 25 & 2 \\
\hline P. nathusii, $\mathrm{C}$ & $5.2,0.9(27)$ & $31.0,5.3(27)$ & $46.5,8.9(27)$ & $17.7,4.6(27)$ & 1 & 29 & 1 \\
\hline P. nathusii, D & $67.9,4.4(5)$ & $39.6,6.8(5)$ & $46.5,7.9(5)$ & $20.7,5.2(5)$ & 4 & 15 & 4 \\
\hline P. pipistrellus, B & $55.6,25.0(28)$ & $18.9,3.3(175)$ & & $15.9,2.0(123)$ & 5 & 39 & 1 \\
\hline P. pipistrellus, C & $15.4,7.2(168)$ & $36.2,5.0(168)$ & $55.6,5.9(168)$ & $32.5,4.9(168)$ & 2 & 23 & 1 \\
\hline P. pipistrellis, D & $29.6,5.9(175)$ & $18.1,1.5(175)$ & $29.7,4.5(175)$ & $14.6,0.9(175)$ & 8 & 15 & 3 \\
\hline P. pygmaeus, $\mathrm{C}$ & $19.4,2.2(5)$ & $31.0,2.8(5)$ & $56.4,7.2(5)$ & $21.5,0.9(5)$ & 1 & 35 & 1 \\
\hline P. pygmaeus, D & $27.3,2.2(13)$ & $22.0,0.9(13)$ & $40.5,2.8(13)$ & $18.1,0.6(13)$ & 3 & 22 & 2 \\
\hline V. murinus, D & $180.0,16.8(181)$ & $12.9,0.5(377)$ & $36.6,4.3(377)$ & $8.6,0.8(377)$ & 4 & 28 & 4 \\
\hline
\end{tabular}

frequencies $<40 \mathrm{kHz}$ of long duration $(63-198 \mathrm{~ms}$; Table 2). Calls of type B consist of high numbers of short pulses $(<10 \mathrm{~ms})$ that begin at high frequencies and end at lower frequencies. Therefore, they are rapidly descending frequency-modulated (FM) notes, without any constant part. Type $\mathrm{C}$ calls also are frequency modulated, but typically have a curved sonagraphic structure. If the frequency is constant, then it is of small bandwidth, compared to type A calls. They are produced as single sounds of short duration (5-58 ms; Table 2), or sometimes as double pulses. Type D song-like calls have a complex sonagraphic structure that typically consists of several different pulses or of several similar frequency-modulated elements and also constant parts (Fig. 3).

Discriminant analysis of the calls with the seven variables freq, dur, pulses (number of pulses per time), fmin, fmax, difptype and $c f p$ proved that the calls fell into the four distinguished groups (Fig. 4; Wilks' lambda: 0.01204 ; c. $\left.F_{21,101}=17.617, P<0.0001\right)$. freq and fmin were least discriminating, all other variables contributed significantly to the discrimination between groups (call types) (Table 3 ). With the variables chosen, 100\% of type 


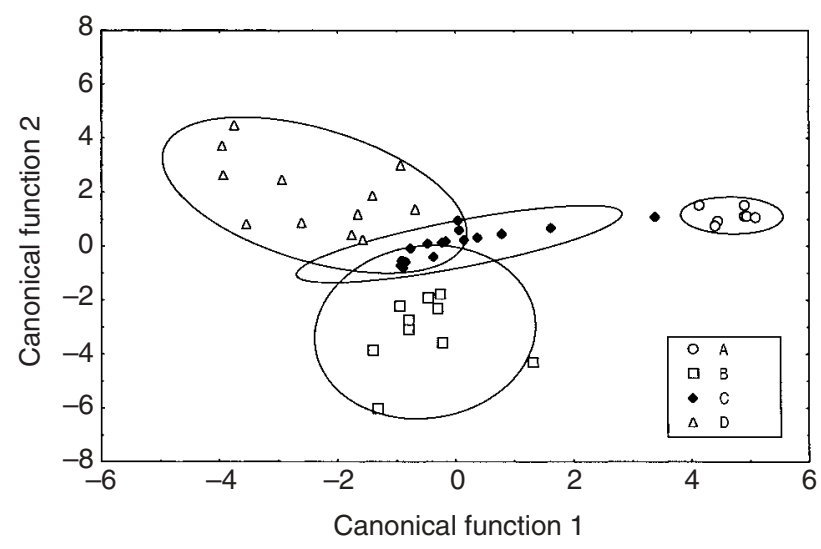

Fig. 4. Distribution of call types A-D of 16 European bat species on first two canonical axes. Large circles enclose areas with $95 \%$ probability of including calls of each group.

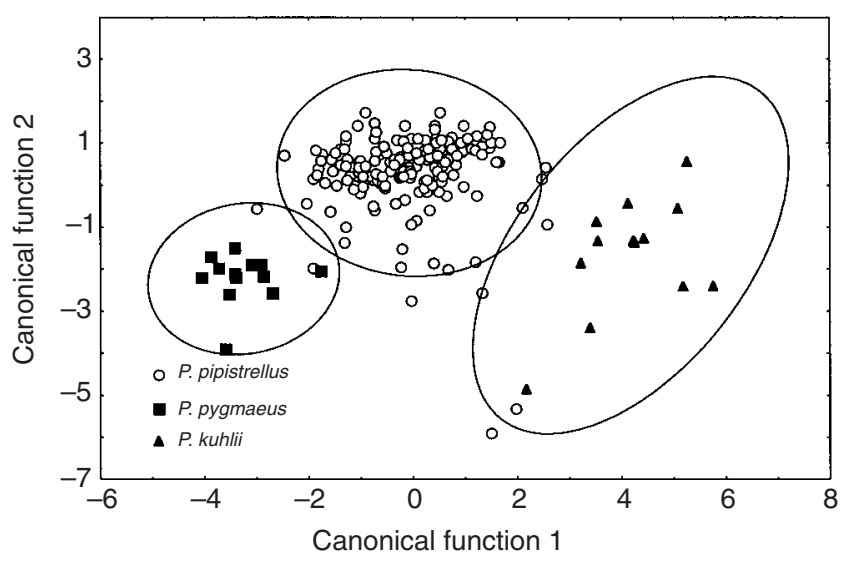

Fig. 5. Distribution of type D calls of Pipistrellus pipistrellus, P. pygmaeus and $P$. kuhlii on first two canonical axes. Large circles enclose areas with $95 \%$ probability of including calls of each group.

Table 3. Discriminant analyses of call types. Call types were chosen as groups (4) with the independent variables freq, dur, pulses (number of pulses per time), fmin, fmax, difptype (number of different pulses per call) and $c f p$ (change of frequency per pulse with time; maximum cfp-values for calls with different pulses; $\mathrm{kHz}$ )

\begin{tabular}{|c|c|c|c|c|c|c|}
\hline Variable & $\begin{array}{l}\text { Wilks' } \\
\text { lambda }\end{array}$ & $\begin{array}{l}\text { Partial } \\
\text { lambda }\end{array}$ & $\begin{array}{l}F \text {-remove } \\
(3,35)\end{array}$ & $P$ & Tolerance & $R^{2}$ \\
\hline freq & 0.012975 & 0.927674 & 0.90958 & 0.446299 & 0.205897 & 0.794103 \\
\hline$d u r$ & 0.016179 & 0.743930 & 4.01580 & 0.014789 & 0.877775 & 0.122225 \\
\hline pulses & 0.029372 & 0.409787 & 16.80341 & 0.000001 & 0.925615 & 0.074385 \\
\hline fmin & 0.013104 & 0.918492 & 1.03531 & 0.388938 & 0.247782 & 0.752218 \\
\hline fmax & 0.028214 & 0.426599 & 15.68141 & 0.000001 & 0.131158 & 0.868842 \\
\hline difptype & 0.056113 & 0.214499 & 42.72365 & 0.000000 & 0.891150 & 0.108850 \\
\hline$c f p$ & 0.039218 & 0.306904 & 26.34742 & 0.000000 & 0.239326 & 0.760674 \\
\hline
\end{tabular}

A, B and C calls were reclassified correctly, and $94 \%$ of type C (14 of 15 calls; the exception is N. noctula C3 which is statistically grouped to A with the chosen variables), with a total of $98 \%$ grouped correctly.

All four types of calls were emitted from bats at their maternity roosts (Table 1). Here the production of social calls was accompanied by intensive swarming of adults coming back from foraging. Social calls most often came from individuals residing inside the roosts, but bats flying outside also emitted social calls.

Pair-wise ('tandem') flights often were observed in eight of the species (M. brandtii, M. nattereri, M. bechsteinii, N. leisleri, E. serotinus, P. pipstrellus, P. pygmaeus, $M$. daubentonii), whereby one bat followed another one that was close by. Social calls of type $\mathrm{C}$ accompanied tandem flights occasionally, with only one animal often producing echolocation calls in this situation.

Chase flights of two bats were observed in foraging habitats of $M$. daubentonii, as in Nyctalus leisleri, $N$. noctula and in the genus Pipistrellus. All of the species P. pipistrellus, P. pygmaeus, $P$. nathusii and $P$. kuhlii often emitted social calls of type D in this flight situation. During chase flights, high-frequency variants of calls of type C also were recorded. Social calls of type C1, D1 and D2 were emitted during chase flights of $N$. noctula individuals. During chase flights, $N$. leisleri produced type $\mathrm{B} 1$ and $\mathrm{D}$ calls. During flight, all species produced predominantly type $\mathrm{C}$ and $\mathrm{D}$ social calls (Table 1 ).

In $M$. bechsteinii and $N$. leisleri, during movement of adults with their infants to another roost, social calls of type $\mathrm{C}$ were recorded from bats inside the old roost, as well as from flying bats. Bats that were caught or that experienced other kinds of severe interference most often emitted type B calls.

\section{General types of social calls vary in different bat species}

Statistical data (Table 2) and discriminant function analysis revealed differences in the social call types of different bat species and showed which call parameters contributed most to the interspecific separation of calling types. This variability was analysed in the genera Pipistrellus and Myotis.

Type D calls of P. pipistrellus, P. pygmaeus and P. kuhlii have similar sonagrams, whereas this calling type in $P$. nathusii looks somewhat different. Also for the type $\mathrm{D}$ calls of $P$. pipistrellus, $P$. pygmaeus, and P. kuhlii, discriminant function analysis (Fig. 5, Table 4) of 201 recorded calls, with dur, fmin, fmax and freq as variables, showed that the calls could be clearly distinguished (Wilk's lambda: $0.25263 ; F_{8,390}=48.241$, $P<0.0001)$. The mean absolute discriminant coefficients 
Table 4. Mean absolute discriminant coefficients $\left(\left|b_{j}\right|\right)$ and reclassification results of interspecific comparisons of social calls within the bat genera Pipistrellus and Myotis

\begin{tabular}{|c|c|c|c|c|c|c|c|}
\hline \multirow[b]{2}{*}{ Genera and species } & \multirow[b]{2}{*}{ Type of call } & \multicolumn{4}{|l|}{ Variable } & \multirow{2}{*}{$\begin{array}{l}\text { No. of calls } \\
\text { evaluated }\end{array}$} & \multirow{2}{*}{$\begin{array}{l}\text { Mean of correct } \\
\text { reclassifications (\%) }\end{array}$} \\
\hline & & $d u r\left(\left|b_{j}\right|\right)$ & freq $\left(\left|b_{j}\right|\right)$ & $f \max \left(\left|b_{j}\right|\right)$ & $\operatorname{fmin}\left(\left|b_{j}\right|\right)$ & & \\
\hline Pipistrellus & & 0.11 & 0.61 & 0.44 & 0.29 & 201 & 93.6 \\
\hline P. pipistrellus & $\mathrm{D}$ & & & & & 175 & 93.2 \\
\hline P. pygmaeus & $\mathrm{D}$ & & & & & 13 & 92.9 \\
\hline P. kuhlii & $\mathrm{D}$ & & & & & 13 & 100.0 \\
\hline Myotis & & 0.13 & 0.46 & 0.72 & 0.24 & 976 & 89.1 \\
\hline M. bechsteinii & $\mathrm{C}$ & & & & & 527 & 87.8 \\
\hline M. brandtii & $\mathrm{C}$ & & & & & 315 & 70.2 \\
\hline M. daubentonii & $\mathrm{C} 2$ & & & & & 69 & 100.0 \\
\hline M. nattereri & $\mathrm{D}$ & & & & & 65 & 86.2 \\
\hline
\end{tabular}

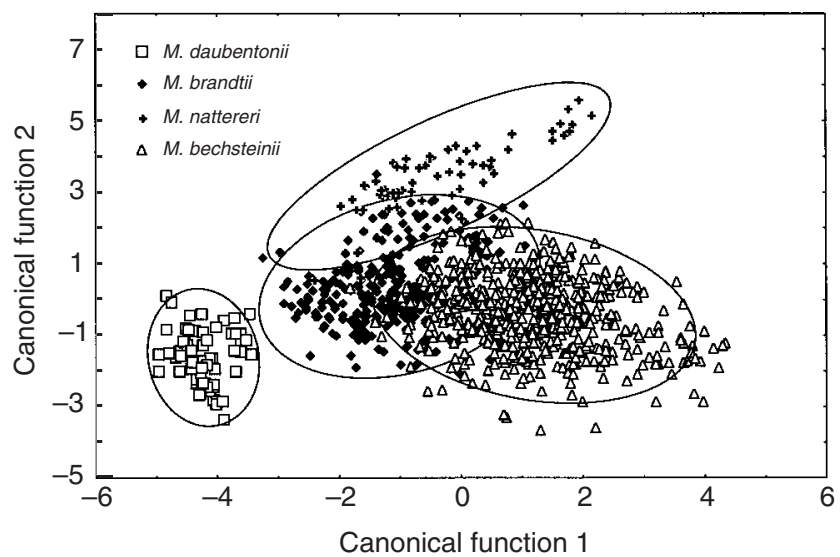

Fig. 6. Distribution of calls of type $\mathrm{C}$ of Myotis brandtii and M. bechsteinii from maternity roosts, as well as of calls of type $\mathrm{C} 2$ of foraging M. daubentonii, and of D from M. nattereri, on first two canonical axes. Large circles enclose areas with $95 \%$ probability of including calls of each group.

$\left|b_{j}\right|$ showed that the variable freq has most influence on group distinction (Table 4). A reclassification of the data confirmed the separation of groups by species.

Interspecific variability of social calls from maternity roosts of Myotis species was measured by discriminant analysis of calling type $\mathrm{C}$ of $M$. brandtii and of $M$. bechsteinii, type D of $M$. nattereri, as well as of call type $\mathrm{C} 2$ of foraging $M$. daubentonii for a comparison. Discriminant analysis from 976 calls and reclassification of the data showed that group isolation is possible (Fig. 6), thus calls of each species were discriminated from all others (Wilk's lambda: $0.13801 ; F_{12,2564}=238.00$, $P<0.0001)$. Mean absolute discriminant coefficients showed that fmax had the largest discriminatory effect, followed by freq (Table 4).

\section{Social calls vary in different individuals of bat species}

Social calls of similar type not only vary among species, but also vary intraspecifically. The variability of calling types depended on different variables in different species
(Table 5). Discriminant analysis with dur, fmin, fmax and freq as variables and calls from different mating roosts of Nyctalus noctula as groups differentiated as many call groups ('variants') of types C3 and D2 as there were different roosts recorded and analysed (Figs $7 \& 8$ ). From six tree roosts of this species, we recorded 241 social calls of type C3, and 310 calls of type D2. Both types of calls were separated by discriminant analysis into six variants, which represented the six different origin sites of the calls (for call type C3, Wilk's lambda: 0.12357; $F_{20,770}=33.837, P<0.0001$; for call type D2, Wilk's lambda: $0.00144 ; F_{35,1256}=134.13, P<0.0001$ ).

Variants are not restricted to different bat social groups, or roost sites. In Myotis myotis and in Eptesicus serotinus, variants were recorded from infants of single roost sites (Table 5). Seven variants of calling type C of M. myotis were distinguished among 171 calls from one roost in the roof of a house (Wilk's lambda: $0.00052 ; F_{24,562}=181.39$, $P<0.0001)$. At least five variants were present among 55 calls of type $C$ of $E$. serotinus from one roost site in the attic of a church (Wilk's lambda: $0.05967 ; F_{16,144}=13.666$, $P<0.0001$ ).

In $P$. pipistrellus individual males emitted specific variants of call type D (Wilk's lambda: 0.00010; $\left.F_{76,152}=18.833, P<0.0001\right)$. From five different mating, or advertisement sites, 61 calls of the complex D type were recorded from male individuals. Discriminant analysis showed that they could be distinguished by their sonagraphic parameters, with $d u r$ and freq being the most discriminating variables (Fig. 9, Table 5).

\section{DISCUSSION}

The present comparative study and evaluation of bat social calls shows that common sonagraphic structures are present in a large number of species, while variable parameters make most calls species as well as individual specific. Calls of 16 bat species could be ordered into four groups according to their sonagraphic parameters. The groups ('calling types') occur independent of the species investigated. These different calling types possibly have common meanings or functions in the 
Table 5. Mean absolute discriminant coefficients $\left(\left|b_{j}\right|\right)$ of intraspecific comparisons of different variants of distinct bat social calls. $n$, number of calls evaluated

\begin{tabular}{|c|c|c|c|c|c|c|}
\hline \multirow[b]{2}{*}{ Species } & \multirow[b]{2}{*}{ Type of call } & \multicolumn{4}{|l|}{ Variable } & \multirow[b]{2}{*}{$n$} \\
\hline & & $d u r\left(\left|b_{j}\right|\right)$ & freq $\left(\left|b_{j}\right|\right)$ & $f \max \left(\left|b_{j}\right|\right)$ & $\operatorname{fmin}\left(\left|b_{j}\right|\right)$ & \\
\hline Myotis myotis & $\mathrm{C}$ & 0.14 & 0.75 & 0.48 & 0.46 & 171 \\
\hline Eptesicus serotinus & $\mathrm{C}$ & 0.20 & 0.26 & 0.96 & 0.62 & 55 \\
\hline \multirow[t]{7}{*}{ Nyctalus noctula } & $\mathrm{C} 3$ & 0.35 & 0.28 & 0.56 & 0.09 & 241 \\
\hline & D2 (total) & 0.12 & 0.25 & 0.04 & 0.12 & 310 \\
\hline & D2 element 1 & 0.09 & 0.04 & & 0.41 & \\
\hline & D2 element 2 & 0.12 & 0.01 & & 0.08 & \\
\hline & D2 element 3 & & 0.38 & & 0.43 & \\
\hline & D2 element 4 & & 0.12 & & 0.06 & \\
\hline & D2 element 5 & & 0.01 & & 0.01 & \\
\hline \multirow[t]{6}{*}{ Pipistrellus pipistrellus } & $\mathrm{D}$ (total) & 0.35 & 0.46 & 0.04 & 0.04 & 61 \\
\hline & D element 1 & 0.06 & 0.59 & 1.25 & & \\
\hline & D element 2 & 0.15 & 0.10 & 0.08 & & \\
\hline & D element 3 & 0.40 & 0.26 & 0.24 & & \\
\hline & D element 4 & 0.14 & 0.63 & 0.48 & & \\
\hline & $\mathrm{D}$ element 5 & 0.94 & 0.42 & 0.00 & & \\
\hline
\end{tabular}

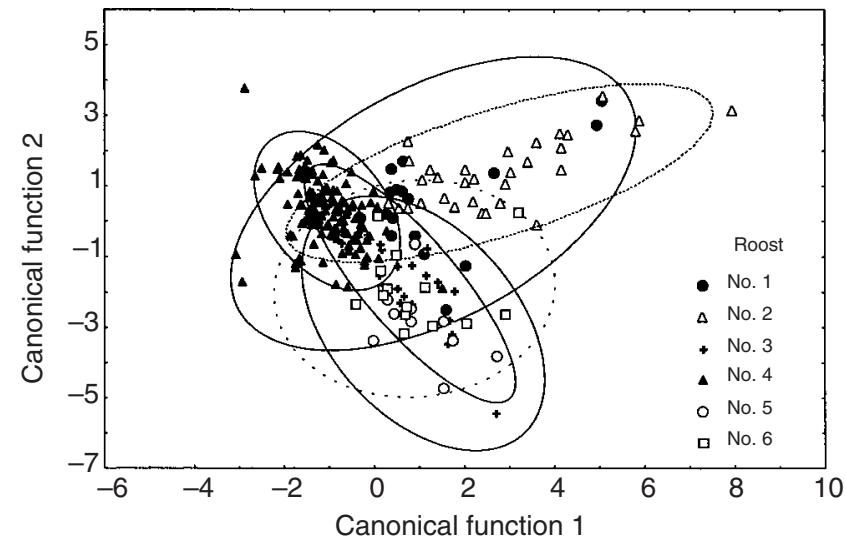

Fig. 7. Distribution of calls of type $\mathrm{C} 3$ from six different roosts (nos 1-6) of Nyctalus noctula on first two canonical axes. Large circles enclose areas with $95 \%$ probability of including calls of each group.

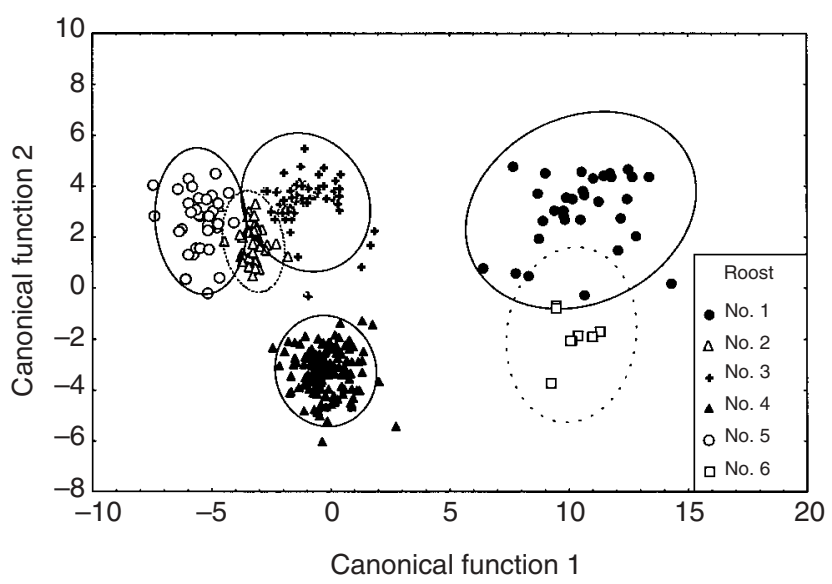

Fig. 8. Distribution of calls of type D2 from six different roosts (nos 1-6) of Nyctalus noctula on first two canonical axes. Large circles enclose areas with $95 \%$ probability of including calls of each group.

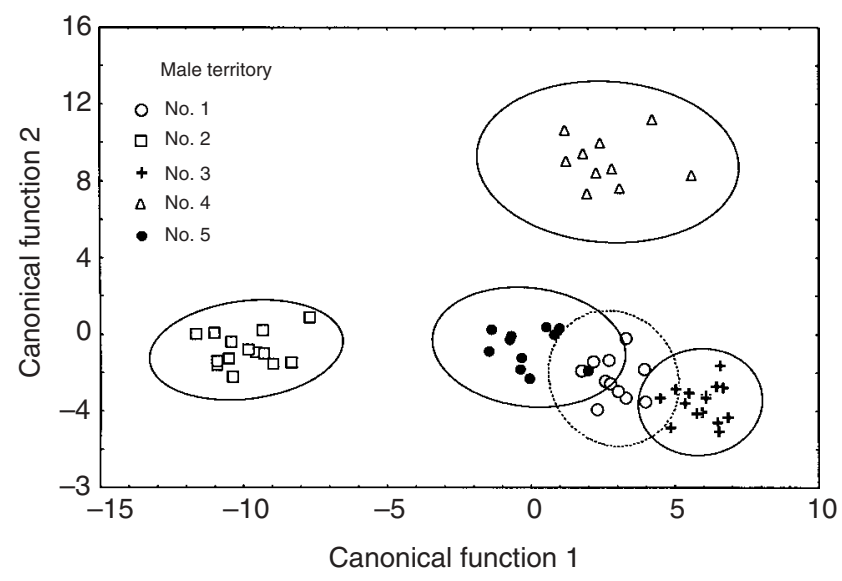

Fig. 9. Distribution of calls of type D of individual male $P$. pipistrellus in five different male territories on first two canonical axes. Large circles enclose areas with $95 \%$ probability of including calls of each group.

different bat species. Analyses of their variability showed that most have species-specific features. The species $M$. daubentonii, M. brandtii, M. nattereri and M. bechsteinii, as well as $P$. pipistrellus, P. pygmaeus, $P$. kuhlii and $P$. nathusii could be discriminated by their social calls. Moreover the distinct call types have intraspecific variability, which should be important for individual recognition in bats.

Type A calls were classified in M. lucifugus as agonistic or aggressive calls, and may also function as a threat (Barclay et al., 1979; Fenton, 1985). This unspecific, noisy call often occurs in bat colonies with many individuals. This kind of social call has a broad band frequency and contains several harmonics of low frequencies; therefore the calls are relatively far reaching (Lawrence \& Simmons, 1982), and can be heard outside the roosts. Possibly, localization of roosts becomes possible for bats flying 
outside, but nearby communication may also be a function of this calling type.

Type B calls apparently express an increased irritation. During interference (e.g. when bats were caught) this calling type was dominant. The calls are species-specific and may also occur in interactions between females and their pups (Kolb, 1981). They were recorded in the present work at maternity roosts, before bats left and after they arrived at the roost. In P. pipistrellus and P. pygmaeus the 'distress calls' (Fenton et al., 1976) attract conspecifics (Russ et al., 1998) and thereby possibly contribute to deter predators.

Type C calls are characteristic for interactions of females and pups. These curved type social calls function as 'isolation calls' and additionally as 'direction calls' (Fenton, 1985) whereby after foraging, female bats are able to find and recognize their pups among many individuals in the colony. A presupposition for acoustic recognition through individual calls is a very high variability of the calls, which was detected in this type of social call for several bat species (Brown, 1976; Kolb, 1981; Schmidt et al., 1981; Rother \& Schmidt, 1985; Thomson et al., 1985; Balcombe, 1990; Jones et al., 1991; Scherrer \& Wilkinson, 1993). Variability and the possibility for discrimination rely on the sonagraphic parameters dur, freq, fmax and fmin (Gelfand \& McCracken, 1986; Jones et al., 1991; Scherrer \& Wilkinson, 1993), as was measured in the present work in M. myotis and in E. serotinus. Since bats can interpret calls totally (they can hear the 'melody') instead of punctually (e.g. fmax describes the moment of highest frequency only), further and fine differences in individual calls may be distinguishable by the bats. Type $\mathrm{C}$ advertisement calls of males possibly develop from isolation calls of pups and therefore attract females.

Recognition of females by their pups is also possible. This was observed in Antrozous pallidus by Brown (1976) and in Phyllostomus discolor by Rother \& Schmidt (1985). Social calls of the females that differ individually in their frequency structures in $P$. discolor and in T. brasiliensis mexicana are responsible for this feature (Esser \& Schmidt, 1989; Balcombe \& McCracken, 1992). In Rhinolophus ferrumequinum nippon, an individual variability and mutual recognition of calls is achieved by a synchronized development with a special time course of calls and their frequencies in females and pups (Matsumura, 1981). In large bat colonies this recognition of females by their pups allows a reduction of costs for females by decreasing search time. Solitary bat species do not need individual long-distance recognition by females and pups. Location of pups by their mothers should be possible by memory of the roost site and in special cases by unspecific isolation calls. Indeed, in pups of the solitary species Lasiurus cinereus, individual specific isolation calls were not detected (Koehler \& Barclay, 1988).

Type $\mathrm{C}$ calls also seem to be important in tandem flights of bats. In N. noctula pups may learn to locate the different roost sites of a maternity colony by following their mothers (Heerdt \& Sluiter, 1965). Infants of several species, when able to fly, follow their mothers during foraging (Brown, 1976; Vaughan, 1976). Thereby type C calls may be used as a contact signal, as was detected in P. pipistrellus and $M$. bechsteinii in the present work. Tandem flights may also be significant for young females for the location of mating roosts, since males of certain species (e.g. M. myotis) do not have special advertisement behaviour.

Adult bats also increase their local knowledge by this 'following behaviour' (Racey \& Swift, 1985; Wilkinson, 1995). The behaviour was shown to increase the success of foraging (Wilkinson, 1992a). Social relatedness was not important for one animal to follow another (Wilkinson, 1992b). Female greater spear-nosed bats Phyllostomus hastatus live in stable groups of unrelated bats and use social calls to co-ordinate foraging movements. Bats may benefit from this group foraging (Wilkinson \& Boughman, 1998). Calls differ between female social groups and cave colonies, and bats perceive these acoustic differences. The group distinctive structure of calls arises through vocal learning. Females change call structure when group composition changes, resulting in increased similarity among new social group mates (Boughman, 1998).

Type D social calls may predominantly act in mate attraction behaviour, but may also function in agonistic interactions between bats in defence of a food patch (Barlow \& Jones, 1997a). The calling type is of a complex structure and therefore allows for high variability, as was observed in several of the European species, which were investigated. It is species-specific and the variability furthermore may allow for individuality in the call (Barlow \& Jones, 1997b). The high variability of type D calls of $N$. noctula, and of P. pipistrellus males, that was observed in the present study, may allow individual recognition of adults. If sexual selection occurs, females may recognize distinct males by individual type $\mathrm{D}$ social calls. As a mating system, resource defence polygyny occurs in P. pipistrellus (Lundberg \& Gerell, 1986). The species exhibit sexual segregation with male territories and female aggregates in maternity colonies. Males defend their territory and individual-specific social calls may help females find distinct territory owners. Furthermore, sexual selection by females, on the basis of complex songs of males that represent their overall fitness, may also explain the variability of type D calls. Inter-individual variability should evolve, if adaptive advantages favour the selection of respective genotypes. The 'neighbourstranger discrimination' (Falls, 1982), where recognition of neighbours diminishes costs of defence to the defence of strangers without territory, should select for individual calls in territorial bat species.

Micro- and macrogeographic variation in the vocalizations of bats, as is well known from birds (e.g. Mundinger, 1982), seems not to be significant, at least in those bat species that migrate long distances and have panmictic populations (e.g. N. noctula). In more locally restricted populations, for example of $P$. kuhlii, microgeographic variation resulting from population isolation may occur, but such variation may instead be an adaptation to different habitat structures (Russo \& Jones, 1999). 


\section{Acknowledgements}

We thank Helmut J. Schmidt, Claudia Weber (both Kaiserslautern), and Andreas Kiefer (Mainz) for support of the work, and Nathan Riser and Elissa Murphy (Northeastern University, U.S.A.) for linguistic corrections of an earlier version of the manuscript.

\section{REFERENCES}

Altringham, J. D. (1996). Bats - biology and behaviour. Oxford: Oxford University Press.

Avery, M. I., Racey, P. A. \& Fenton, M. B. (1984). Short distance location of hibernaculum by little brown bats (Myotis lucifugus). J. Zool. (Lond.) 204: 588-590.

Balcombe, J. P. (1990). Vocal recognition of pups by mother Mexican free-tailed bats, Tadarida brasiliensis mexicana. Anim. Behav. 39: 960-966.

Balcombe, J. P. \& Fenton, M. B. (1988). The communication role of echolocation calls in vespertilionid bats. In Animal sonar: 625-628. Nachtigall, P. E. \& Moore, P. W. B. (Eds). New York: Plenum Press.

Balcombe, J. P. \& McCracken, G. F. (1992). Vocal recognition in Mexican free-tailed bats: do pups recognize mothers? Anim Behav. 43: 79-87.

Barclay, R. M. C. (1982). Interindividual use of echolocation calls: eavesdropping by bats. Behav. Ecol. Sociobiol. 10: 271-275.

Barclay, R. M. C., Fenton, M. B. \& Thomas, D. W. (1979). Social behavior of the little brown bat, Myotis lucifugus. II. Vocal communication. Behav. Ecol. Sociobiol. 6: 137-46.

Barlow, K. E. \& Jones, G. (1997a). Function of pipistrelle social calls: field data and a playback experiment. Anim. Behav. 53: 991-999.

Barlow, K. E. \& Jones, G. (1997b). Differences in songflight calls and social calls between two phonic types of the vespertilionid bat Pipistrellus pipistrellus. J. Zool. (Lond.) 241: 315-324.

Boughman, J. W. (1997). Greater spear-nosed bats give groupdistinctive calls. Behav. Ecol. Sociobiol. 40: 61-70.

Boughman, J. W. (1998). Vocal learning by greater spear-nosed bats. Proc. R. Soc. Lond. B Biol. Sci. 265: 227-233.

Brown, P. (1976). Vocal communication in the Pallid Bat, Antrozous pallidus. Z. Tierpsychol. 41: 34-54.

De Fanis, E. \& Jones, G. (1995). Post-natal growth, motheryoung interactions and development of vocalisations in the vespertilionid bat Plecotus auritus. J. Zool. (Lond.) 235: 85-97.

Esser, K. H. \& Schmidt, U. (1989). Mother-infant communication in the lesser spear-nosed bat Phyllostomus discolor (Chiroptera, Phyllostomidae) - evidence for acoustic learning. Ethology 82: 156-168.

Falls, J. B. (1982). Individual recognition by sounds in birds. In Acoustic communication in birds 2: Song learning and its consequences: 237-278. Kroodsma, D. E., Miller, E. H. \& Ouellet, H. (Eds). New York: Academic Press.

Fenton, M. B. (1985). Communication in the Chiroptera. Bloomington: Indiana University Press.

Fenton, M. B. (1986). Design of bat echolocation calls: implications for foraging ecology and communication. Mammalia 50: 193203

Fenton, M. B. (1987). Echolocation: introduction to the symposium. In Recent advances in the study of bats: 119-121. Fenton, M. B., Racey, P. A. \& Rayner, J. M. V. (Eds). Cambridge: Cambridge University Press.

Fenton, M. B. (1994). Assessing signal variability and reliability: 'to thine ownself be true'. Anim. Behav. 47: 757-764.

Fenton, M. B. \& Bell, G. P. (1981). Recognition of species of insectivorous bats by their echolocation calls. J. Mammal. 62 : 233-243.
Fenton, M. B., Belwood, J. J., Fullard, J. H. \& Kunz, T. H. (1976). Response of Myotis lucifugus (Chiroptera: Vespertilionidae) to calls of conspecifics and to other sounds. Can. J. Zool. 54: 14431448 .

Gelfand, D. L. \& McCracken, G. F. (1986). Individual variation in the isolation calls of Mexican free-tailed bat pups (Tadarida brasiliensis mexicana). Anim. Behav. 34: 1078-1086.

Griffin, D. R., Webster, F. A. \& Michael, C. R. (1960). The echolocation of flying insects by bats. Anim. Behav. 8: 141-154.

Gustin, M. K. \& McCracken, G. F. (1987). Scent recognition between females and pups in the bat Tadarida brasiliensis mexicana. Anim. Behav. 35: 13-19.

Heerdt, P. F. van \& Sluiter, J. W. (1965). Notes on the distribution and behaviour of the Noctule Bat (Nyctalus noctula) in the Netherlands. Mammalia 29: 463-477.

Helversen, O. von \& Helversen, D. von (1994). The 'advertisement song' of the lesser noctule bat (Nyctalus leisleri). Folia Zool. 43: 331-338.

Jones, G. (1995). Flight performance, echolocation and foraging behaviour in noctule bats Nyctalus noctula. J. Zool. (Lond.) 237: 303-312.

Jones, G., Hughes, P. M. \& Rayner, J. M. V. (1991). The development of vocalizations in Pipistrellus pipistrellus (Chiroptera: Vespertilionidae) during post-natal growth and the maintenance of individual vocal signatures. J. Zool. (Lond.) 225 : 71-84.

Kalko, E. K., Schnitzler, V. \& Schnitzler, H. U. (1989). The echolocation and hunting behavior of Daubenton's bat, Myotis daubentoni. Behav. Ecol. Sociobiol. 24: 225-238.

Kalko, E. K., Schnitzler, V. \& Schnitzler, H. U. (1993). Plasticity in echolocation signals of European pipistrelle bats in search flight: implications for habitat use and prey detection. Behav. Ecol. Sociobiol. 33: 415-428.

Koehler, C. F. \& Barclay, R. M. R. (1988). The potential for vocal signatures in the calls of young hoary bats (Lasiurus cinereus). Can. J. Zool. 66: 1982-1985.

Kolb, A. (1977). Wie erkennen sich Mutter und Junges des Mausohrs, Myotis myotis, bei der Rückkehr vom Jagdflug wieder? Z. Tierpsychol. 44: 423-431.

Kolb, A. (1981). Entwicklung und Funktion der Ultraschallaute bei den Jungen von Myotis myotis und Wiedererkennung von Mutter und Jungem. Z. Säugetierkd. 46: 12-19.

Kulzer, E. (1958). Untersuchungen über die Biologie von Flughunden der Gattung Rousettus. Z. Morphol. Ökol. Tiere 47: 374-402.

Kulzer, E. (1962). Über die Jugendentwicklung der AngolaBulldogfledermaus Tadarida (Mops) condylura (A. Smith, 1833) (Molossidae). Säugetierkd. Mitt. 10: 116-124.

Lawrence, B. D. \& Simmons, J. A. (1982). Measurements of atmospheric attenuation at ultrasonic frequencies and the significance for echolocation by bats. J. acoust. Soc. Am. 71: 585-590.

Leonard, M. L. \& Fenton, M. B. (1984). Echolocation calls of Euderma maculatum (Chiroptera: Vespertilionidae): use in orientation and communication. J. Mammal. 65: 122-126.

Lundberg, K. \& Gerell, R. (1986). Territorial advertisement and mate attraction in the bat Pipistrellus pipistrellus. Ethology 71: $115-124$

Masters, W. M. \& Jacobs, S. C. (1989). Target detection and range resolution by the big brown bat (Eptesicus fuscus) using normal and time-reversed model echoes. J. comp. Physiol. A sens. neural. behav. Physiol. 166: 65-73.

Masters, W. M., Raver, K. A. S. \& Kazial, K. A. (1995). Sonar signals of big brown bats, Eptesicus fuscus, contain information about individual identity, age and family affiliation. Anim. Behav. 50: $1243-1260$.

Matsumura, S. (1981). Mother-infant communication in a horseshoe bat (Rhinolophus ferrumequinum nippon): vocal communication in three-week-old infants. J. Mammal. 62: 20-28. 
Miller, L. A. \& Degn, H. J. (1981). The acoustic behavior of four species of vespertilionid bats studied in the field. J. Comp. Physiol. 142: 67-74.

Mundinger, P. C. (1982). Microgeographic and macrogeographic variation in the acquired vocalizations of birds. In Acoustic communication in birds 2: Song learning and its consequences: 147-208. Kroodsma, D. E., Miller, E. H. \& Ouellet, H. (Eds). New York: Academic Press.

Obrist, M. K. (1995). Flexible bat echolocation: the influence of individual, habitat and conspecifics on sonar signal design. Behav. Ecol. Sociobiol. 36: 207-219.

Racey, P. A. \& Swift, S. M. (1985). Feeding ecology of Pipistrellus pipistrellus (Chiroptera: Vespertilionidae) during pregnancy and lactation. I. Foraging behaviour. J. Anim. Ecol. 54: 205-215.

Rother, G. \& Schmidt, U. (1985). Die ontogenetische Entwicklung der Vokalisation bei Phyllostomus discolor (Chiroptera). Z. Säugetierkd. 50: 17-26.

Russ, J. M., Racey, P. A. \& Jones, G. (1998). Intraspecific responses to distress calls of the pipistrelle bat, Pipistrellus pipistrellus. Anim. Behav. 55: 705-713.

Russo, D. \& Jones, G. (1999). The social calls of Kuhl's pipistrelles Pipistrellus kuhlii (Kuhl, 1819): structure and variation (Chiroptera: Vespertilionidae). J. Zool. (Lond.) 249: 476-48.

Rydell, J. (1990). Behavioural variation in echolocation pulses of the northern bat, Eptesicus nilssoni. Ethology 85: 103-113.
Scherrer, J. A. \& Wilkinson, G. S. (1993). Evening bat isolation calls provide evidence for heritable signatures. Anim. Behav. 46: 847-860.

Schmidt, U., Joermann, G. \& Schmidt, C. (1981). Struktur und Variabilität der Verlassenheitslaute juveniler Vampirfledermäuse (Desmodus rotundus). Z. Säugetierkd. 47: 143-149.

Thomson, C. E., Fenton, M. B. \& Barclay, R. M. R. (1985). The role of infant isolation calls in mother-infant reunions in the little brown bat, Myotis lucifugus (Chiroptera: Vespertilionidae). Can. J. Zool. 63: 1982-1988.

Vaughan, T. A. (1976). Nocturnal behaviour of the African false vampire bat (Cardioderma cor). J. Mammal. 57: 227-248.

Wilkinson, G. S. (1992a). Information transfer at evening bat colonies. Anim. Behav. 44: 501-518.

Wilkinson, G. S. (1992b). Communal nursing in evening bats. Behav. Ecol. Sociobiol. 31: 225-235.

Wilkinson, G. S. (1995). Information transfer in bats. In Ecology, evolution and behaviour of bats. Symp. zool. Soc. Lond. No. 67 : 345-360. Racey, P. A. \& Swift, S. M. (Eds). Oxford: Clarendon Press.

Wilkinson, G. S. \& Boughman, J. W. (1998). Social calls coordinate foraging in greater spear-nosed bats. Anim. Behav. 55: $337-$ 350 .

Zingg, P. E. (1988). Search calls of echolocating Nyctalus leisleri and Pipistrellus savii (Mammalia: Chiroptera) recorded in Switzerland. Z. Säugetierkd. 53: 281-293. 